\section{Construção do conhecimento contextualizado e cultura popular no ensino de ciências através da produção de vídeos digitais no contexto da folkcomunicação científica e tecnológica}

\author{
Construction of contextualized knowledge and popular \\ culture in the teaching of sciences through the production \\ of digital videos in the context of scientific and \\ technological folkcommunication
}

\section{RESUMO}

Esse trabalho aborda a construção do conhecimento contextualizado através da participação popular no ensino de ciências através da produção de vídeos digitais no contexto da folkcomunicação. A partir do reconhecimento das limitações da escola e da concepção tradicional de educação apresentamos os resultados de uma pesquisa de intervenção participante que analisou como a produção de vídeos digitais por discentes de uma escola da Rede Municipal do município de Itapissuma (PE) contribui para a construção do conhecimento contextualizado no ensino de Ciências. A metodologia utilizada foi de natureza qualitativa, empregando entrevistas semiestruturadas e observação participante para a coleta de dados junto a dezoito discentes e um docente. Anteriormente ao início dos trabalhos dos alunos foram realizadas oficinas de criação de vídeo digital, seguidas de entrevistas, na fase pós-produção. Os resultados evidenciam que a assunção do papel de produtores culturais contribui significativamente para o processo de construção do conhecimento, e para a posta em prática, forma contextualizada, dos conteúdos curriculares abordados. A publicação dos vídeos em redes sociais, seguida de debates e diálogos a respeito de conceitos científicos que impactam o cotidiano da comunidade onde vivem (poluição, doenças sexualmente transmissíveis) estabeleceu por outro lado um nexo entre vida, cultura popular e o ensino em Ciências, conforme os elementos de uma Folkcomunicação Científica e Tecnológica. Dessa forma, reconhecendo a importância e a necessidade de mediações pedagógicas que promovam a interação, a colaboração, o trabalho em equipe e o desenvolvimento da autonomia, nossos resultados validam a produção de vídeo digital enquanto tecnologia educacional capaz de estabelecer novas formas de compreensão do mundo.

Palavras-chave: Vídeo digital. Ensino de Ciências. Folkcomunicação Científica e Tecnológica.
Sebastião Vieira e

MarCelo SabBatin

Universidade Federal de Pernambuco. Centro de Educação, Recife/PE, Brasil. 


\section{ABSTRACT}

This work deals with the construction of contextualized knowledge through popular participation in science teaching through the production of digital videos in the context of folkcommunication. From the recognition of the limitations of the school and the traditional conception of education we present the results of a participatory intervention research that analyzed how the production of digital videos by students of a school in the Municipal Network of the municipality of Itapissuma (PE) contributes to the construction of knowledge contextualized in science teaching. The methodology used was of qualitative nature, employing semi-structured interviews and participant observation for the data collection with eighteen students and one teacher. Prior to the beginning of the students' work, workshops were created to create digital video, followed by interviews, in the post-production phase. The results show that the assumption of the role of cultural producers contributes significantly to the process of knowledge construction and to the contextualized implementation of the curricular contents. The publication of the videos in social networks, followed by debates and dialogues about scientific concepts that impact the daily life of the community where they live (pollution, sexually transmitted diseases), on the other hand, established a nexus between life, popular culture and science teaching, according to the elements of a Scientific and Technological Folk. Thus, recognizing the importance and necessity of pedagogical mediations that promote interaction, collaboration, teamwork and the development of autonomy, our results validate the production of digital video as an educational technology capable of establishing new ways of understanding the world.

Keywords: Digital video. Science teaching. Folk Scientific and Technological Communication.

\section{INTRODUÇÃO}

\section{O mundo contemporâneo encontra-se permeado por mídias, sobretudo as} digitais; neste contexto, a produção e o uso do vídeo digital converte-se em objeto de pesquisa, sobretudo na área de Educação como possibilidade de inovação pedagógica e de contextualização de conteúdos curriculares em sala de aula. A linguagem audiovisual enquanto proposta pedagógica, e se utilizada de forma criteriosa, acena com possibilidades. Neste sentido de inserção das tecnologias digitais na escola, conjuntamente com a divulgação científica dos trabalhos realizados pelos discentes, especificamente os vídeos digitais, foi o tema de um trabalho desenvolvido por um dos autores enquanto professor da Educação Básica com um grupo de jovens do município de Itapissuma, Estado de Pernambuco.

A produção de documentários na disciplina de Direitos Humanos e Cidadania (DHC) estabeleceu uma dinâmica de produção de vídeos digitais como ferramenta pedagógica e de avaliação. O papel ativo de produção de conhecimento e de interação despertou o senso investigativo do autor, resultando numa pesquisa de mestrado [1], cujo objetivo foi relacionar a produção de vídeo digital enquanto ferramenta 
pedagógica com a construção do conhecimento contextualizado dos conteúdos curriculares trabalhados em sala de aula no ensino de Ciências, assim como as contribuições para a comunidade escolar envolvida. A pesquisa teve como questionamento norteador a seguinte pergunta: que contribuições podem trazer a produção de vídeos digitais por discentes de uma escola municipal para a construção do conhecimento contextualizado no ensino de Ciências? Esta experiência de intervenção com uso da tecnologia educacional também foi analisada sob a ótica da Folkcomunicação e, mais especificamente, da Folkcomunicação Científica e Tecnológica. Ao envolver os alunos, suas famílias e a comunidade local num debate contextualizado envolvendo conceitos de ciência e tecnologia, entendemos que a proposta se alicerça numa concepção participativa de comunicação, superando os esquemas lineares e hegemônicos do jornalismo científico de massa.

\section{OS DILEMAS DA EDUCAÇÃO CONTEMPORÂNEA}

Apesar das diversas críticas que viram a partir dos anos 1960 e 1970 uma instituição reprodutora das desigualdades sociais, a estrutura da escola e da Educação ao longo do tempo vem aos poucos se modificando. A escola ainda carrega em sua "cultura” uma lógica tradicionalista e metodológica, mas na contemporaneidade podemos vislumbrar movimentos de adaptação ao contexto histórico, político, econômico, tecnológico, principalmente através do uso das tecnologias digitais de informação e comunicação (TDICs). Na concepção de Silva e Correia [2], "nesse cenário, cabe refletir sobre a importância das novas tecnologias ${ }^{1}$ para a aprendizagem. Elas realmente podem contribuir para esse processo ou isso é algo utópico, ilusório? Os educandos só aprendem da forma como se aprendia trinta anos atrás?”. Dito de outra forma, aos pesquisadores da tecnologia educacional cabe desvendar o real potencial de transformação da tecnologia, mais além do mero uso em discursos permeados pela noção de racionalidade técnica. O principal desafio da educação no mundo atual é integrar a escola a novas situações de aprendizagem, inserindo na cultura escolar metodologias que dinamizem o ensino e a aprendizagem, transformando os discentes em atores autônomos, capazes de construir saberes práticos associados com os conteúdos curriculares mediados pela escola.

O vídeo digital na educação Um interessante recurso de potencialização do ensino e da aprendizagem o vídeo digital traz imagens e sons que dinamizam as aulas, trazem o mundo "lá de fora", rompendo com o esquema transmissivo da educação tradicional. Mais do que isso, produzir e compartilhar é uma característica da cultura digital, com o auxílio de tecnologias que progressivamente se encontram difundidas, como o celular (smartphone), tablets, e câmeras digitais. Segundo Marcondes Filho [3] "na era digital o homem possui uma relação diferente com o seu meio e suas ideias".

1 Cabe ressaltar que o termo "novas" encontra-se atualmente em desuso, conforme observamos que estas tecnologias estão inseridas na sociedade há pelo menos cinco décadas. 
Televisão e vídeo são sensoriais, visuais, linguagem falada, linguagem musical e escrita. Linguagens que interagem superpostas, interligadas, somadas e de todas as maneiras. Televisão e vídeo nos seduzem, informam, entretêm, projetam em outras realidades (no imaginário), em outros tempos e espaços [4].

O vídeo, juntamente à televisão, tem um papel importante no processo de aprendizagem dos conteúdos escolares em sala de aula, ajudando o docente a criar estratégias pedagógicas. Neste sentido, destacamos não a utilização destes recursos no esquema transmissão-recepção (passividade), mas no de produção-transmissão-recepção (autonomia), conforme os discentes possam se tornar produtores, utilizando as ferramentas das tecnologias digitais de informação e comunicação para organizar, planejar, captar e editar imagens e sons. Assim, pode se revelar um auxílio para a construção de conhecimentos e para a interpretação de temas científicos no contexto do ensino de Ciências. Para Belloni e Gomes [5] “[... ] o vídeo, como suporte pedagógico, estimula as crianças a mobilizarem seus referenciais televisuais, suas competências específicas de leitura televisual, gerando grande motivação, inclusive para outras aprendizagens como a da leitura”.

De acordo com Freire e Rangel [6] "o desenvolvimento da tecnologia digital tornou possível um novo modelo de comunicação, cuja estrutura, ao menos em tese, é mais dialógica”. Metodologias que estratégias participativas são revisitadas no contexto educacional, fazendo com que os professores renovem seus métodos didáticos, e enriqueçam as possibilidades de inovação pedagógica, trazendo os discentes para esse contexto de mediação e de participação em sala de aula. Como efeito sinergético, aumenta a motivação de toda comunidade escolar, propiciando uma maior participação nas propostas pedagógicas.

\section{O ENSINO DE CIÊNCIAS EM QUESTIONAMENTO}

Brevemente, poderíamos resumir o ensino de Ciências no Brasil com apenas uma palavra: descontextualização. Além dela, este ensino caracterizou-se historicamente por ser distante da realidade dos conhecimentos prévios dos discentes, limitando-se à teorização e à memorização de conceitos científicos. Como consequência, de forma geral os alunos não compreendem a importância das Ciências em seu cotidiano, tornando assim passivos diante às situações vivenciadas em sociedade. Nesta lógica, estabeleceu-se na cultura uma noção da ciência como algo "difícil" de se aprender. Os objetivos do ensino de Ciências na Educação Básica visa levar aos discentes a uma alfabetização científica entendida como uma compreensão crítica do meio social, ambiental e cultural e como percepção da importância da ciência para o desenvolvimento social, para a formação da cidadania e para a contribuição para melhoraria da qualidade de vida das pessoas. Segundo Taglieber [7], "não é necessário somente ensinar os conceitos científicos, mas principalmente como estes conceitos e princípios foram descobertos - o processo científico de inquirição, a natureza do conhecimento científico". Porém, o que se constata e observa-se em grande parte da Educação Básica é um ensino de Ciências segmentado, tendo como foco principal a transmissão de 
conteúdos, formando os discentes para serem meros receptores de informações, não tendo nenhuma ação prática diante das disciplinas de caráter científico.

\section{FOLKCOMUNICAÇÃO CIENTÍFICA E TECNOLÓGICA, ENTRE O COTIDIANO DOS ALUNOS E A CULTURA POPULAR}

No atual panorama, os alunos a todo o momento criam e idealizam conteúdos por meio do uso das tecnologias digitai, além de se comunicarem através das redes sociais. O processo de interagir, conversar, trocar ponto de vistas, entre pessoas de camadas populares e de forma paralela aos meios de comunicação de massa é denominada Folkcomunicação. "A margem", sem contar com formação específica e sem possuir voz própria na sociedade e levando ainda em conta seu status socioeconômico, poderiam ser considerados um grupo de exclusão. A Folkcomunicação, em outras palavras, é a expressão da cultura popular, em termos de imaginário, de expressividade e de sua linguagem singular, por meio da comunicação. Mais além do folclore, ela traz as percepções reais dos alunos e da comunidade para o ambiente escolar; especificamente em Ciências podemos relacionar a produção de conhecimento mediante as tecnologias digitais de informação e comunicação, assim como a posterior discussão, debate e participação que estes produtos engendram, com o conceito de Folkcomunicação Científica e Tecnológica [8;9].

\section{PERCURSO METODOLÓGICO}

A pesquisa foi realizada em campo escolar na cidade de Itapissuma (PE) entre os meses de agosto e dezembro de 2016. Sua orientação foi de natureza qualitativa ${ }^{2}$, fazendo uso da participação, da observação e da intervenção direta do pesquisador junto aos discentes do $9^{\circ}$ ano do Ensino Fundamental. Para tal foram realizadas oficinas de produção e planejamento dos vídeos, junto à observação e convivência durante o processo de produção multimídia das por parte das equipes. A Escola Municipal João Bento de Paiva, segundo dados extraídos da própria instituição, funciona nos três turnos com turmas de Ensino Fundamental Anos Finais ${ }^{3}$ e Educação de Jovens e Adultos (EJA). A primeira visita ao campo de pesquisa aconteceu no dia 17 de agosto de 2016, visando conhecer o docente da disciplina do ensino de Ciências e o perfil das turmas. Nesta primeira aproximação, o objetivo foi explicar a pesquisa e seus objetivos ao docente e apresentar a proposta do estudo. Cada equipe participou da oficina de confecção de vídeo digital denominada de "Oficina de Cultura Científica e Tecnologias Digitais".

2 Na concepção de Ludke e André [10], a pesquisa qualitativa "envolve a obtenção de dados descritivos, obtidos no contato direto do pesquisador com a situação estudada, enfatiza mais o processo do que o produto e se preocupa em retratar a perspectiva dos participantes".

3 Compreendidos entre o 60 e ० 90 anos, são considerados essenciais para a inserção do aluno na vida em e para a sociedade, valorizando a busca constante do conhecimento e da emancipação. 
Os participantes da pesquisa, dezoito discentes do $9^{\circ}$ ano, dividido em quatro equipes ${ }^{4}$, tiveram como função produzir vídeos digitais sobre um conteúdo trabalhado em sala de aula na disciplina de Ciências, podendo ser este: curtas-metragens, documentários, séries, talk shows, etc. Foram formadas quatro equipes, ficando cada uma com um conteúdo curricular solicitado pelo professor da disciplina: Ondas Sonoras e Eletromagnéticas; Reprodução dos Seres Vivos; Biodiversidade e Doenças Sexualmente Transmissíveis (DSTs).

A escolha do tipo de produção audiovisual a ser utilizada ficou a critério dos discentes, de acordo com sua criatividade. O professor da disciplina de Ciências ficou responsável por ser o mediador das divisões das equipes, pelo sorteio dos conteúdos e pela avaliação das produções realizadas ao logo do processo. As atividades aconteceram no laboratório da escola, utilizando como recursos tecnológicos de mediação equipamentos da escola, a saber tablets, smartphones, filmadora, pendrive, computadores, notebooks, além do software nativo Windows Movie Maker ${ }^{5}$ e do aplicativo VivaVideo ${ }^{6}$, utilizado por alguns discentes em seus dispositivos pessoais. Esses dois aplicativos foram utilizados pelas equipes de maneira exitosa, dinâmica, criativa e interativa durante o processo de produção. O VivaVideo, por ser um aplicativo possível de utilização em smartphones acabou sendo utilizando de forma eficaz, não apresentado dificuldade no manuseio. Já o com o Windows Movie Maker alguns discentes apresentaram algumas dificuldades, por ser um aplicativo com várias informações e interatividade.

Como se percebe, utilizamos uma abordagem de pesquisa participante. Serrano e Collazo, [11] afirmam que "o processo participante na investigação nasce do esforço de concretizar a promoção do ser humano de forma participante e organizada”. Nela, os sujeitos tornam se participantes de todo processo pedagógico de construção do saber, agindo, atuando de forma ativa diante de determinado objeto e assimilando esses conhecimentos para serem utilizados na prática, em determinadas situações cotidianas ou pedagógicas. A pesquisa se fundamentou em três procedimentos de coleta de dados. O questionário buscou diagnosticar o perfil sociocultural dos pesquisados, suas características, seus hábitos e crenças, além de sua relação com as tecnologias digitais em seu cotidiano.

Ou seja, esse primeiro contato para mapear o perfil dos pesquisados foi importante para o desenvolvimento da pesquisa, pois o pesquisador pôde traçar seu planejamento para início da pesquisa e assim fortalecer os demais instrumentos de coleta. Já a observação participante visou compreender o percurso planejado metodologicamente registrado através do poder de observação e detalhamento do pesquisador. Finalmente, a

\footnotetext{
4 Por motivos de ética científica, não referenciaremos os sujeitos por seus nomes verdadeiros, mas por pseudônimos.

5 Segundo Souza, Carvalho e Moita, [12] "é um simples software de edição de vídeo, sendo ainda em parte desconhecido como interface gratuita do sistema operacional Windows".

6 Este aplicativo "permite ao usuário criar e editar vídeos a partir de mídias da biblioteca do celular. Recheado de recursos que vão de efeitos especiais a inserção de música nos vídeos, o aplicativo transforma o aparelho em uma poderosa central de produção audiovisual. A navegação dentro do aplicativo é bem simples. A tela inicial apresenta as opções de Captura, Filme de Fotos, Editar, Videoclipe, Estúdio, Materiais, Colagem e Em Destaque" [13].
} 
última etapa na coleta dos dados, a entrevista, visou compreender os saberes relevados pelos discentes na produção do conhecimento contextualizado através da produção do vídeo digital, suas experiências e saberes construídos.

A avaliação da produção audiovisual de cada equipe ocorreu por meio da análise do docente da disciplina, que utilizou uma ficha de avaliação com indicadores de qualidade, fazendo perguntas orais também no momento da arguição. A apresentação dos vídeos digitais e a avaliação dos trabalhos produzidos ocorreram na sala de aula no formato de seminário: cada equipe apresentou o vídeo elaborado e explicou a temática abordada. Em seguida o docente avaliou seguindo os critérios mencionados. Os discentes responderam à entrevista semiestruturada de forma individualizada visando verificar quais conhecimentos foram adquiridos no desenvolvimento da produção e se a metodologia aplicada contribuiu para o processo de aquisição de saberes na disciplina de Ciências.

O docente da disciplina também foi entrevistado a respeito da avaliação dos vídeos apresentados pelas equipes e de sua análise sobre os trabalhos produzidos. Com os vídeos produzidos pelos discentes foi criado um canal próprio no YouTube, (rede social com foco em disseminação de vídeos), visando compartilhar os conhecimentos construídos. O nome escolhido para este canal foi TV Ciências $-9^{\circ}$ Ano.

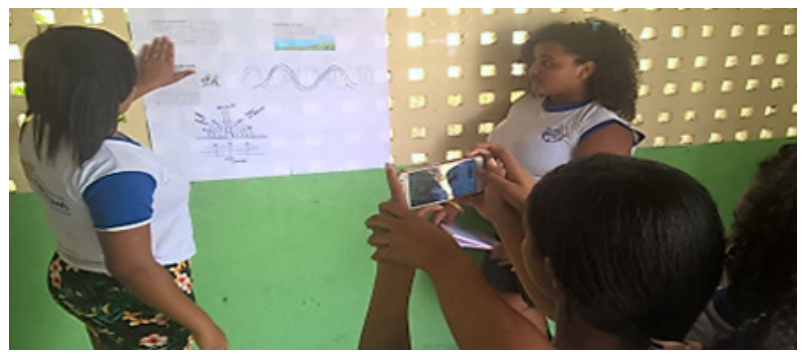

Figura 1 - Situações contextualizadas trazidas pelos discentes. Uso das imagens dos estudantes. Fonte: Fotografia do autor.

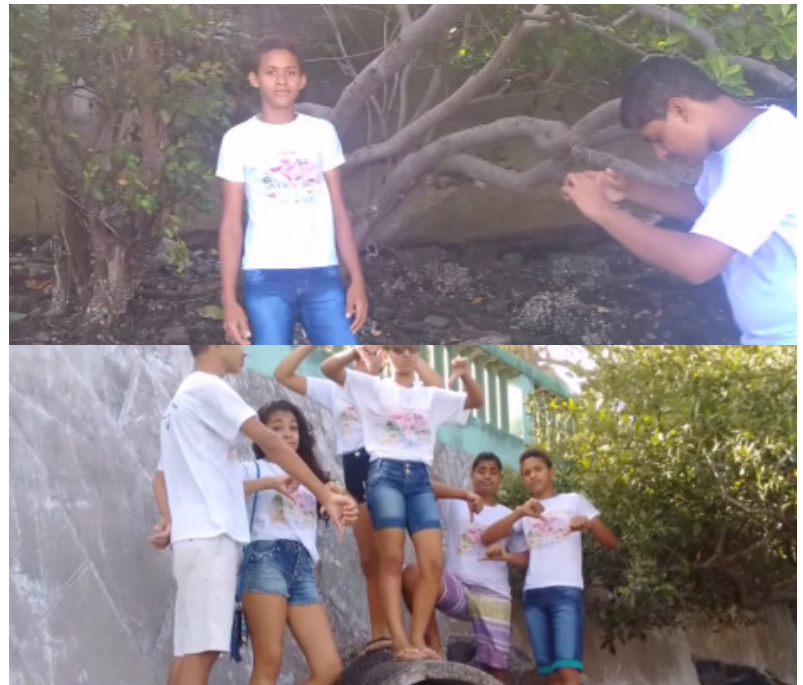

Figura 2 - Bastidores da gravação do vídeo digital formato teleaula. Fonte: Fotografia do autor.

OBS: No início da oficina cada discente recebeu um termo de autorização de uso de imagem para os pais assinarem, liberando o uso das imagens dos mesmos para produção e serem divulgadas em trabalhos científicos. A orientação foi a de devolver os termos assinados no dia de realização da produção (campo para filmagem), sendo que estes registros se encontram em posse dos autores. 


\section{RESULTADOS E DISCUSSÃO}

Em relação às contribuições para a construção do conhecimento contextualizado no ensino de Ciências, pudemos observar uma concordância entre os alunos, ao longo de todas as equipes. Para a discente Ana Paula, "para produzir o vídeo foi preciso estudar mais e isso melhora a aprendizagem." A discente Mariele relata que "produzir um vídeo ( ... e é uma forma de conhecimento para a vida”.Já para a discente Mariana, "[o vídeo] está explicando e mostrando as ondas sonoras na prática”. O discente João destaca que "o vídeo me fez entender mais sobre o assunto indo além da explicação do professor”. O discente também percebeu a influência direta de temas relacionados à ciência para seu cotidiano "pois a poluição prejudica a vida das pessoas, mostrando a realidade da poluição e do desmatamento”. E o discente Mario comparou as mídias, sendo o vídeo "melhor do que ler um livro, bem melhor estudando e criando o roteiro, ajuda a entender melhor o assunto”.

Responsabilidade e autonomia são identificadas na fala de César, que considera que o vídeo "ajudou, porque fiquei focado no trabalho, em fazer algo certo e não fazer ruim”. O trabalho com a produção de vídeo digital no ensino de Ciências trouxe contribuições na construção do conhecimento contextualizado, pois os alunos vivenciaram algumas situações práticas que ajudaram no entendimento no conteúdo estudado. Tudo isso reforça a tese que estamos sustentando nessa pesquisa, que a produção de vídeo digital no contexto escolar contribui para a construção cognitiva em sala de aula, ajudando a melhorar a assimilação do conteúdo curricular.

Acrescenta-se que as teorias e práticas associadas à informática na educação vêm repercutindo em nível mundial, justamente porque as ferramentas e mídias digitais oferecem à didática, objetos, espaços e instrumentos capazes de renovar as situações de interação, expressão, criação, comunicação, informação, e colaboração, tornando-a muito diferente daquela tradicionalmente fundamentada na escrita e nos meios impressos. [12]

Ao relacionar teoria e prática os alunos são capazes de construir conhecimento, assumindo o papel de protagonistas do processo e desenvolvendo autonomia. O estudo e a produção do vídeo digital auxiliaram a compreensão de conceitos: paralelamente a estar em sala, vendo explicações, com a produção os discentes foram capazes de ampliar sua apreensão do conteúdo curricular, ao entrar em contato direto com o assunto através das situações práticas. Relacionamos as afirmações dos discentes com a concepção que Moran [14] traz sobre a importância do vídeo, quando ele destaca que:

O vídeo é sensorial, visual, linguagem falada, linguagem musical e escrita. Linguagens que interagem superpostas, interligadas, somadas, não separadas. Daí a sua força. Somos atingidos por todos os sentidos e de todas as maneiras. O vídeo nos seduz, informa, entretém, projeta em outras realidades (no imaginário), outros tempos e espaços. O vídeo combina a comunicação sensorial-cinestésica com audiovisual a intuição com a lógica, a emoção com a razão. Combina, mas começa pelo sensorial, pelo emocional e pelo intuitivo, para atingir posteriormente o racional. 
A função pedagógica da produção de um vídeo digital é vasta, conseguindo desenvolver várias competências justamente por conta de seu dinamismo característico. De acordo com Schneider, Caetano e Ribeiro [15]. "a tecnologia está cada vez mais presente na vida dos alunos e em virtude desse dinamismo, a produção de vídeos digitais de curta duração está cada vez mais popular”.

O vídeo possui um potencial de sedução, devido a características intrínsecas de sua linguagem, como imagens, sons, efeitos, cores. Já diante da etapa de uma produção de um vídeo digital esse poder de atração aumenta, pois quem vivencia essa experiência se depara com um processo de interação, colaboração, trabalho em equipe, organização, envolvendo o "saber ouvir" e o uso eficaz da linguagem.

Por estes motivos, a produção em si já contribui para o desenvolvimento dos discentes envolvidos. Schneider, Caetano e Ribeiro [15] destacam que "o vídeo tem um poder de ilustração muito forte, prende atenção quando bem estruturado e elaborado. Tem movimento, áudio e, muitas vezes, é autoexplicativo". Contudo, destacamos que com relação à comparação do uso do vídeo com o livro didático, não há por que considerar o vídeo exclusivamente sem o auxílio de diversos momentos de troca e de interação e mesmo de outras tecnologias. O livro-texto, o computador, as discussões em sala de aula; todo processo pedagógico é importante em sala de aula na construção do conhecimento.

Neste sentido, o a produção do vídeo é muito mais um estímulo para que processos dialógicos e interativos de ensinar-aprender que um fator determinante de êxito. Diante dos resultados também recuperamos Moran, Masetto e Behrens [4] no que se refere ao "saber pesquisar, escolher, comparar e produzir novas sínteses, individualmente e em grupo, é fundamental para ter chances na nova sociedade que estamos construindo". Assim, estes autores destacam ainda a importância da pesquisa, interação, da seleção e escolha de estratégias a serem utilizados na produção do saber.

Diante dessa discussão, Sancho [16] afirma que "as tecnologias usadas no ensino escolar, modelam o desenvolvimento dos indivíduos e a sua forma de apreensão do mundo". Poderíamos dizer que um trabalho escolar desenvolvido por meio da produção de um vídeo digital desperta no discente uma expansão de concepção de mundo, seu interesse e sua curiosidade. Porém, é preciso destacar que o vídeo digital de forma isolada é responsável pela promoção da construção de um conhecimento, mas, todo processo didático, incluindo a mediação por parte do docente e a interação com os pares. Enfatizamos que a mediação docente diante esse processo de utilização das tecnologias digitais e outras práticas pedagógicas é de suma importância para o sucesso dessa metodologia de ensino. Segundo Silva e Oliveira [17] o "uso do vídeo em sala de aula acaba norteando habilidades diversificadas mediante a formação do aluno como, por exemplo, desenvolver a interação entre os sujeitos”. De acordo com Pimenta e Ghedin [18] "ensinar não é a mesma coisa que fazer aprender, ainda que, muitas vezes, para fazer o aluno aprender, o professor tenha que ensinar". Segundo as entrevistas, percebemos que as equipes desenvolveram qualidades essenciais para o crescimento intelectual, ou seja, a autonomia, o senso participativo e dialógico, perceptíveis na eficiência e na organização da produção.

Diante dessa análise Freire [19] enfatiza que "a ligação mais forte do saber pensar é a gestação da autonomia”. Finalmente, a publicação dos vídeos produzidos nas redes 
sociais permitiu um debate que extrapolou os limites da sala de aula, envolvendo pais, outros professores, além de pessoas da comunidade. Neste sentido, podemos entender esta aproximação entre cultura popular, conforme a contextualização realizada em cada vídeo, e conhecimento científico através do viés folkcomunicacional:

$\mathrm{Na}$ atualidade, entretanto, tanto a ciência passa por uma revisão epistemológica, como os modelos de sua comunicação necessitam ser reconsiderados, frente aos ideais de envolvimento, empoderamento e participação que são característicos das concepções de desenvolvimento local. Como um todo, evidencia-se que possivelmente o principal desafio em relação aos conflitos entre ciência e sociedade diga respeito ao papel político deste processo comunicativo, com o reconhecimento de uma diversidade de interesses e de relações de autoridade e poder existentes. Estabelecer um nexo entre o desafio de se alcançar uma cultura científica generalizada, mais além dos limites de classe socioeconômica, de gênero ou de etnias, entendida como uma ferramenta de promoção do desenvolvimento local, e a perspectiva da assimilação destes saberes não mais partilhados (no sentido de fragmentados), consiste a nosso ver o objeto de uma Folkcomunicação orientada ao campo científico e tecnológico [8].

Para os discentes a produção do vídeo digital ajudou na assimilação do conteúdo curricular, ao mesmo tempo em que se ensinava se aprendia também e essa interação ajudou no entendimento individual do assunto estudado. Assim, a produção do vídeo digital trouxe importantes contribuições para a expansão do conhecimento contextualizado.

\section{CONSIDERAÇÕES FINAIS}

Apresentamos neste estudo uma discussão a contribuição da produção de vídeos digitais na construção do conhecimento contextualizado no ensino de Ciências. Resumida na problemática de que a produção do vídeo digital pode trazer algumas contribuições para os discentes na construção do conhecimento prático, estimulando várias competências e habilidades, promovendo alguns saberes mediante o processo de produção do vídeo, como autorrepresentações pelos próprios sujeitos que participaram da experiência, no esforço para resolver um determinado problema.

Os resultados mostraram que os discentes alcançaram a construção dos conhecimentos contextualizados no ensino de Ciências através da produção do vídeo digital, promoveram articulações através dos conhecimentos revelados na produção do vídeo digital, tais como trabalho colaborativo, senso organizacional, planejamento, estratégias de estudo através de pesquisas e leitura, e realizaram mobilizações visando à construção dos conhecimentos adquiridos no ensino de Ciências através de habilidades como a criatividade, organização, comprometimento, planejamento, trabalho cooperativo, divulgação e debate na Internet, especificamente nas redes sociais. Com isso a pesquisa traz uma contribuição para o entendimento da produção de vídeo e de sua metodologia técnica e pedagógica no contexto educacional, como ferramenta auxiliar na construção do conhecimento contextualizado no ensino de Ciências.

Especialmente, destacamos que neste processo de construção cognitiva a produção 
do vídeo proporcionou aos discentes um olhar mais crítico perante o conteúdo estudado. Assim, a produção cultural dos vídeos, a troca de informações e principalmente uma participação significativa dos sujeitos nas dinâmicas sociais e contemporâneas pode ser compreendida pela ótica da Folkcomunicação Científica e Tecnológica.

A partir da análise, evidenciamos que a produção de vídeos digitais promoveu nos discentes uma construção cognitiva mais significativa e próxima ao cotidiano, despertando neles um dinamismo na busca de informações de forma crítica e criativa na elaboração do vídeo. Os discentes construíram uma forma diferenciada de entender o conteúdo curricular estudado em sala, mediante novos aprendizados e novas formas de compreensão do mundo.

\section{REFERÊNCIAS}

[1] VIEIRA, Sebastião Silva. A contribuição da produção de vídeos digitais por discentes de uma escola municipal na construção do conhecimento contextualizado no ensino de Ciências. Dissertação de Mestrado. Universidade Federal de Pernambuco. Programa de Pós-Graduação em Educação Matemática e Tecnológica. Recife: UFPE, 2017.

[2] SILVA, Franco Renildo; CORREIA, Sena Emilce. Novas tecnologias e educação: a evolução do processo de ensino e aprendizagem na sociedade contemporânea. Educação e Linguagem, ano 1, p. 23-25, junho 2014.

[3] MARCONDES FILHO, Ciro. Televisão: a vida pelo vídeo. São Paulo: Moderna, 1995 .

[4] MORAN, José Manuel, MASETTO, Marcos; BEHRENS, Marilda Aparecida. Novas tecnologias e mediação pedagógica. 19 ed. Campinas: Papirus, 2012.

[5] BELLONI, Maria Luiza; GOMES, Nilza Godoy. Infância, mídias e aprendizagem: autodidaxia e colaboração. Revista Educação \& Sociedade. Campinas, v. 29, n. 104, p. 717 - 746, out. 2008.p.734.

[6] FREIRE, Wendel; RANGEL, Mary. Educação e tecnologia: texto, hipertexto e leitura. Rio de Janeiro: Wak, 2012.

[7] TAGLIEBER, José. Erno. O Ensino de Ciências nas Escolas Brasileiras. Perspectiva, Florianópolis, p. 91-111, jul./eez 1984.Disponivel em: . Acesso em: 10 dez. 2016.

[8] MACIEL, Betania; SABBATINI, Marcelo. Mais além de Prometeu: elementos seminais para uma Folkcomunicação Científica e Tecnológica aplicada ao desenvolvimento local. In: XXXV Congresso Brasileiro de Ciências da Comunicação, 2012, Fortaleza. Anais ... São Paulo: Sociedade Brasileira de Estudos Interdisciplinares da Comunicação, 2012.

[9] MACIEL, Betania; SABBATINI, Marcelo. Novas perspectivas de modelos participativos de Comunicação Pública da Ciência e Desenvolvimento Local: classificação dos meios da Folkcomunicação Científica e Tecnológica. In: XXXVI Congresso Brasileiro de Ciências da Comunicação, 2013, Manaus. Anais ... São Paulo: Intercom, 2013

[10] LUDKE, Menga; ANDRÉ, Marli. A Pesquisa em educação: abordagens 
qualitativas. São Paulo: EPU, 1986.

[11] SERRANO, Garcia. Irma; COLLAZO, W. Rosalio. Contribuciones portorriqueñas a la psicologia social-comunitaria. Rio Piedras: Editorial de La Universidad de Puerto Rico, 1992.

[12] SOUZA, Robson. Pequeno et al. Tecnologias digitais na educação. Campina Grande: EDUEPB, 2011.

[13] FREITAS, Breno Fonseca. Telas que ensinam: smartphones e aplicativos de celular na construção de vídeos instrucionais para sala de aula. In: Congresso Regional sobre Tecnologias na Educação, Anais ... Natal: CEUR-WS, 2016. v.1667.

[14] MORAN, José Manuel.O vídeo na sala de aula. Comunicacão e Educacão, São Paulo, v. 2,.jan./abr. 1995.

[15] SCHNEIDER, Catiúcia Klug; CAETANO, Lélia; RIBEIRO, Luis. Otoni. Meireles. Análise de Vídeos Educacionais no youtube: caracteres e legibilidade. Revista Novas Tecnologias na Educação, CINTED-UFRGS, Porto Alegre, v. 10, p. 35-39, 2012.

[16] SANCHO, Juana. Maria. Para uma tecnologia educacional. Porto Alegre: Artmed, 1998.

[17] SILVA, Rosilma Ventura; OLIVEIRA, Elizagela Mercado. As possibilidades do uso do vídeo como recurso de aprendizagem de aula do $5^{\circ}$ ano. Pesquisa em Educação: desenvolvimento, ética e responsabilidade social.

[18] PIMENTA, Selma, Garrido; GHEDIN, Evandro. Professor reflexivo no Brasil: gênese e crítica de um conceito. São Paulo: Cortez, 2002.

[19] FREIRE, Paulo. Pedagogia da Autonomia. São Paulo: Paz e Terra, 2010.

SEBASTIÃO DA SILVA VIEIRA mestre na linha de pesquisa Educação Tecnológica pela Universidade Federal de Pernambuco-UFPE. - EDUMATEC - UFPE (2017), Técnico em Informática (Desenvolvimento de Software) pela Escola Técnica Estadual Professor Agamemnon Magalhães, ETEPAM, Brasil.(2014-2015). Graduado em Licenciatura Plena em Pedagogia pela Faculdade de Ciências Humanas e Sociais de Igarassu - FACIG (2008), Especialista em Pedagogia Empresarial pela Faculdade Joaquim Nabuco - FJN (2010) - e-mail: sebastianfacig@gmail.com.udos Culturais (EACH-USP)e Educação (FEUSP) - e-mail: lppiassi@usp.br.

MARCElo SABBATINI doutor em Teoria e História da Educação - Universidad de Salamanca (Espanha) em 2004. Pós-doutorado realizado no Programa de Extensão Rural e Desenvolvimento Local - POSMEX da Universidade Federal Rural de Pernambuco, 2006. Mestre em Comunicação Social, modalidade Comunicação Científica e Tecnológica, Universidade Metodista de São Paulo, 200o. Especialista em Comunicação e Cultura Científica, Universidad de Salamanca, 1999. MBA em Administração de Empresas, foco em Gestão, Fundação Getúlio Vargas, 2009. Engenheiro químico, Universidade Estadual de Campinas, 1997. Professor Adjunto IV do Departamento de Fundamentos Sócio-Filosóficos da Educação do Centro de Educação da Universidade Federal de Pernambuco (UFPE) e professor pesquisador da Universidade Aberta do Brasil (UAB-Capes). Professor do Programa de Pós-Graduação em Educação Matemática e Tecnológica - EDUMATEC-UFPE. 